\title{
PENGARUH MODEL PEMBELAJARAN KOOPERATIF TIPE GROUP INVESTIGATION (GI) DENGAN MEDIA PHOTOVOICE BERBASIS LANSKAP BUDAYA SUBAK TERHADAP PERILAKU BERKELOMPOK SISWA SMP AMARAWATI TAMPAKSIRING
}

\author{
Sang Ayu Made Ika Utari Dewi, Dewa Ayu Puspawati, Deden Ismail \\ Program Studi Pendidikan Biologi, Fakultas Keguruan dan Ilmu Pendidikan, \\ Universitas Mahasaraswati Denpasar
}

\begin{abstract}
Conventional learning process that takes place in the same direction from the teacher to students, causing impaired social aspect or ability groups of students. One model of learning that appropriate to the problem is the type of cooperative learning Group Investigation (GI). GI learning model integrated with the technological aspects of digital cameras and the cultural landscape etnosains subak. This study aimed to investigate the effect of cooperative learning model GI to student group behavior, and how group behavior influence the outcome of photovoice students. The experiment was conducted in Amarawati Tampaksiring junior high school, data collection techniques using group behavior assessment rubrics and photovoice results rubrics assessment. Students learning activities in the classroom and outside the classroom (Subak Pulagan). The results showed there is an increasing number of group behavior score from 235,0 to 430,5, with a significance level of each aspect of the assessment using the Wilcoxon Match Pairs are aspects of group participation ( $p$ $=0.028)$, division of responsibility $(p=0.028)$, quality interactions $(p=0.026)$, and the role of members in the group $(p=0.027)$. This suggests that there are real differences in behavior between groups of students before and after learning. As for the impact of the group behavior to photovoice results of the test using the Spearman Rank Correlation, obtained correlation coefficient $(\rho=0.928)$ is shown with a positive sign, meaning that increasing group behavior is increasing as well the results of the student photovoice. With a significance level $(p=0.008<0.01)$ which indicates that the group behavior of very significant effect on the results of photovoice. Conclusions of this study are given effective learning to improve student groups so with good interaction within the group, then the task is given by making photovoice obtain maximum results.
\end{abstract}

Key words : difference, social aspects, innovative media, significance

\section{PENDAHULUAN}

Sampai saat ini proses pembelajaran pada berbagai jenjang pendidikan di tanah air cenderung masih berlangsung secara konvensional yang didominasi oleh guru tanpa melibatkan partisipasi aktif dari siswa. Padahal pendidikan bertujuan untuk mengembangkan semua potensi yang ada di dalam diri 
siswa, baik aspek kognitif, afektif, dan psikomotorik (Nurdin, 2012). Selain itu pembelajaran yang berlangsung searah yaitu dari guru kepada siswanya menyebabkan lemahnya kemampuan sosial atau berkelompok siswa, karena kurang adanya kesempatan bagi siswa tersebut untuk berinteraksi dengan teman dan gurunya.

Salah satu model pembelajaran yang tepat untuk melibatkan partisipasi aktif dan sekaligus meningkatkan kemampuan sosial siswa adalah model pembelajaran kooperatif tipe Group Investigation $(G I)$. GI merupakan salah satu model pembelajaran yang aktif karena siswa akan belajar melalui proses pembentukan secara individu, serta berbagi pengetahuan maupun tanggung jawab dengan kelompoknya. Pembelajaran kooperatif tipe $G I$ diintegrasikan dengan menerapkan teknologi dan etnosains. Aspek teknologi yang digunakan dalam pembelajaran adalah kamera digital, sedangkan aspek etnosains yang digunakan adalah lanskap budaya subak. Integrasi antara teknologi dan etnosains dapat dikembangkan ke dalam suatu media pembelajaran inovatif yaitu photovoice. Photovoice merupakan media yang digunakan dalam pembelajaran dimana siswa bekerja dalam kelompok dan mengembangkan daya kreativitasnya melalui teknik dan fotografi tertentu, yang menggunakan pesan visual diikuti dengan narasi untuk meningkatkan keefektifan pembelajaran (Nelson, dkk. 2009).

Penerapan pembelajaran kooperatif tipe GI dengan media photovoice yang diintegrasikan dengan aspek teknologi dan etnosains dilakukan sebagai upaya untuk memberikan pengaruh positif terhadap perilaku sosial atau berkelompok siswa sebagai makhluk sosial yang selalu berinteraksi untuk mencapai tujuan bersama. Dengan merancang media pembelajaran yang inovatif dan melibatkan siswa dalam pembuatannya akan memotivasi siswa untuk berpikir kritis terhadap suatu permasalahan, serta berperan aktif dalam proses pembelajaran.

\section{METODE PENELITIAN}

\section{Waktu dan Tempat}

Data dikumpulkan mulai tanggal 02 Januari sampai 13 Februari 2013, dari siswa kelas VII A SMP 
Amarawati Tampaksiring yang berjumlah 36 orang. Penelitian dilaksanakan di dalam kelas dan di luar kelas yaitu areal Subak Pulagan. Sampel dalam penelitian diambil dengan teknik sampling sistematis, dengan melihat urutan populasi sehingga didapatkan kelas VII A sebagai kelas sampel.

\section{Rancangan dan Teknik Pengambilan Data}

Desain penelitian ini adalah PreExperimental dengan model OneGroup Prettest-Posttest. Perlakuan yang diberikan dalam penelitian adalah model pembelajaran kooperatif tipe GI dengan media photovoice berbasis subak. Proses pembelajaran dilaksanakan secara berkelompok, siswa berjumlah 36 orang dibentuk menjadi 6 kelompok. Pemilihan anggota kelompok dilakukan dengan analisis jaringan sosial sehingga kelompok bersifat heterogen baik dari jenis kelamin maupun kemampuannya. Pembelajaran dilaksanakan di dalam kelas dan di luar kelas, di dalam kelas kegiatan siswa adalah belajar mengenai materi ekosistem, kemudian siswa diberikan latihan untuk merancang media photovoice secara berkelompok.
Pengamat akan melakukan pengamatan dan penilaian terhadap perilaku berkelompok siswa yang dikumpulkan dengan rubrik penilaian perilaku berkelompok (Surata, 2009) yang telah digunakan dalam beberapa penelitian sebelumnya. Sedangkan pembelajaran di luar kelas dilaksanakan di areal Subak Pulagan, kegiatan siswa adalah mencari gambar untuk pembuatan photovoice sesuai dengan topik masing-masing yang berkaitan dengan ekosistem subak, dimana hasil akhir photovoice siswa akan dinilai menggunakan rubrik penilaian photovoice (Zlem, 2012).

Validitas dan Reliabilitas Instrumen Validitas rubrik penilaian photovoice diuji menggunakan uji korelasi Product Moment. Dari uji validasi instrumen didapatkan koefisien korelasi dan signifikansi masing-masing aspek yaitu spesifikasi $(\mathrm{r}=0,702 ; \quad \mathrm{p}=0,000), \quad$ komposisi $(\mathrm{r}=0,712 ; \mathrm{p}=0,000)$, visual $(\mathrm{r}=0,355$; $\mathrm{p}=0,033)$, kualitas gambar $(\mathrm{r}=0,378$; $\mathrm{p}=0,023)$, dan narasi $\quad(\mathrm{r}=0,609$; $\mathrm{p}=0,000$ ), dengan demikian instrumen penelitian valid dan dapat digunakan untuk melakukan penilaian terhadap hasil photovoice siswa. Sedangkan uji reliabilitas dilakukan dengan uji intra- 
observer reliabilitas dan inter-observer reliabilitas. Intra-observer reliabilitas merupakan sebuah penilaian dengan pengukur (observer) yang sama pada waktu atau kesempatan yang berbeda (Polgar dkk. dalam Murti, 2011), kemudian data tersebut dikorelasikan dan mendapat koefisien korelasi $(0,793)$ yang menunjukkan adanya reliabilitas yang tinggi. Sedangkan inter-observer reliabilitas merupakan penilaian dengan pengukur (observer) yang berbeda pada jangka waktu bersamaan (Polgar, dkk. dalam Murti, 2011). Kedua sampel tersebut dikorelasikan dan mendapatkan koefisien korelasi sebesar $(0,775)$ yang menunjukkan reliabilitas data cukup tinggi, sehingga dapat digunakan untuk penilaian selanjutnya.

\section{Analisis Data}
Data perilaku berkelompok dianalisis secara kuantitatif menggunakan Uji Wilcoxon Match Pairs. Analisis ini dilakukan untuk mengetahui adanya perbedaan perilaku berkelompok siswa antara sebelum dan sesudah pembelajaran kooperatif tipe GI dengan media photovoice berbasis lanskap budaya subak. Kemudian untuk mengetahui

pengaruh perilaku berkelompok siswa terhadap hasil pembuatan photovoice dianalisis menggunakan uji Spearman Rank-Correlation.

\section{HASIL DAN PEMBAHASAN}

\section{Hasil Penelitian}

\section{Analisis perilaku berkelompok}

Perilaku berkelompok siswa dinilai dengan melakukan pengamatan terhadap 4 aspek meliputi partisipasi kelompok (PK), pembagian tanggung jawab (PTJ), kualitas interaksi (KI) dan peranan anggota dalam kelompok (PADK). Hasil perbandingan perilaku berkelompok antara sebelum dan sesudah pembelajaran menggunakan kooperatif tipe GI berdasarkan skor median dari kedua observer dapat dilihat pada Tabel 1. 
Tabel 1. Perbandingan Penilaian Skor Aspek Perilaku Berkelompok

\begin{tabular}{ccccccccccc}
\hline Kelompok & \multicolumn{9}{c}{ Sebelum } & \multicolumn{4}{c}{ Sesudah } \\
\cline { 2 - 11 } A & PK & PTJ & KI & PADK & Jumlah & PK & PTJ & KI & PADK & Jumlah \\
\cline { 2 - 11 } & 15,5 & 12,0 & 12, & 9,5 & 49,0 & 18,0 & 21,0 & 21,0 & 20,5 & 80,5 \\
B & 11,5 & 10,0 & 10, & 8,5 & 40,0 & 16,5 & 16,0 & 17,5 & 17,5 & 67,5 \\
& & & 0 & & & & & & & \\
C & 11,5 & 9,5 & 8,5 & 9,5 & 39,0 & 16,0 & 15,0 & 18,5 & 18,0 & 67,5 \\
D & 9,0 & 8,5 & 9,0 & 9,5 & 36,0 & 19,0 & 18,0 & 19,0 & 18,5 & 74,5 \\
E & 8,0 & 11,0 & 8,0 & 9,0 & 36,0 & 17,5 & 15,0 & 18,0 & 19,0 & 69,5 \\
F & 9,0 & 8,5 & 8,5 & 9,0 & 35,0 & 17,5 & 17,0 & 18,0 & 18,5 & 71,0 \\
\hline Jumlah & 64,5 & 59,5 & 56, & 55,0 & 235,0 & 104,5 & 102,0 & 112,0 & 112,0 & 430,5 \\
\hline
\end{tabular}

Keterangan : Partisipasi kelompok (PK), Pembagian tanggung jawab (PTJ), Kualitas interaksi (KI), Peranan anggota dalam kelompok (PADK)

Dari hasil perbandingan tersebut, terlihat bahwa jumlah skor perilaku berkelompok siswa mengalami peningkatan dari 235,0 menjadi 430,5. Hal tersebut diperkuat oleh hasil uji Wilcoxon Match Pairs yang menunjukkan adanya perbedaan nyata antara sebelum dan sesudah pembelajaran menggunakan model pembelajaran kooperatif tipe GI pada jumlah skor perilaku berkelompok dengan signifikansi sebesar $\left(Z_{6}=-\right.$ 2,201; $p=0,028)$. Sedangkan hasil uji Wilcoxon Match Pairs pada masingmasing aspek perilaku berkelompok juga menunjukkan adanya perbedaan nyata antara sebelum dan sesudah pembelajaran menggunakan model pembelajaran kooperatif tipe GI. Pada aspek PK $\left(Z_{6}=-2,201 ; p=0,028\right)$, PTJ $\left(Z_{6}=-2,201 ; p=0,028\right), \mathrm{KI}\left(Z_{6}=-2,226\right.$; $p=0,026)$, dan PADK $\left(Z_{6}=-2,207\right.$; $p=0,027$ ). Hal tersebut berarti hipotesis pertama dalam penelitian ini yang menyatakan implementasi model pembelajaran kooperatif tipe Group Investigation (GI) dengan media photovoice berbasis lanskap budaya subak berpengaruh terhadap perilaku berkelompok siswa SMP Amarawati Tampaksiring diterima.

\section{Analisis pengaruh perilaku}

\section{berkelompok terhadap hasil}

\section{photovoice}

Pada saat proses pembelajaran, siswa secara berkelompok membuat photovoice yang menjadi tugas kelompok mereka. Hasil photovoice dinilai dengan melakukan pengamatan terhadap 5 aspek penilaian meliputi Spesifikasi (S), Komposisi (K), Visual (V), Kualitas Gambar (KG), dan Narasi (N). Penilaian hasil photovoice siswa dilakukan terhadap hasil 
sebelum dan sesudah pembelajaran kooperatif tipe GI oleh dua orang observer. Perbandingan penilaian hasil photovoice sebelum dan sesudah

Tabel 2. Perbandingan Penilaian Skor Hasil Photovoice Siswa antara Sebelum dan Sesudah Pembelajaran Kooperatif Tipe GI

\begin{tabular}{|c|c|c|c|c|c|c|c|c|c|c|c|c|}
\hline \multirow[t]{2}{*}{ Kelompok } & \multicolumn{5}{|c|}{ Sebelum } & \multicolumn{6}{|c|}{ Sesudah } & \multirow[b]{2}{*}{$\sum$} \\
\hline & $\mathrm{S}$ & $\mathrm{K}$ & $\mathrm{V}$ & KG & $\mathrm{N}$ & $\sum$ & $\mathrm{S}$ & $\mathrm{K}$ & $\mathrm{V}$ & KG & $\mathrm{N}$ & \\
\hline $\mathbf{A}$ & 1,5 & 2,0 & 2,0 & 1,5 & 1,5 & 8,5 & 3,0 & 2,0 & 3,0 & 3,0 & 2,5 & $1 \overline{3,5}$ \\
\hline B & 1,5 & 2,0 & 2,0 & 2,5 & 1,5 & 9,5 & 2,0 & 2,0 & 2,5 & 3,0 & 3,0 & 12,5 \\
\hline C & 2,0 & 3,0 & 3,0 & 2,5 & 2,0 & 12,5 & 3,5 & 3,0 & 3,0 & 2,5 & 3,0 & 15,0 \\
\hline D & 1,5 & 1,5 & 2,0 & 2,0 & 1,0 & 8,0 & 3,5 & 4,0 & 3,5 & 2,5 & 3,0 & 16,5 \\
\hline $\mathbf{E}$ & 2,0 & 2,0 & 2,0 & 2,5 & 1,0 & 9,5 & 3,5 & 3,0 & 3,0 & 3,5 & 3,0 & 16,0 \\
\hline $\mathbf{F}$ & 2,0 & 2,0 & 2,0 & 2,0 & 3,0 & 11,0 & 4,0 & 4,0 & 3,0 & 3,0 & 3,5 & 17,5 \\
\hline$\sum$ & 10,5 & 12,5 & 13,0 & 13,0 & 10,0 & 59,0 & 19,5 & 18,0 & 18,0 & 17,5 & 18,0 & 91,0 \\
\hline
\end{tabular}

Keterangan : Spesifikasi (S), Komposisi (K), Visual (V), Kualitas Gambar (KG), Narasi $(\mathrm{N})$, Jumlah Skor $(\Sigma)$

Dari hasil perbandingan tersebut, terlihat jumlah skor hasil photovoice siswa mengalami peningkatan dari 59,0 menjadi 91,0. Ditinjau dari segi kelompok, terlihat bahwa kelompok D mengalami peningkatan jumlah skor tertinggi yaitu dari 8,0 menjadi 16,5. Sedangkan jika ditinjau dari aspek penilaian hasil photovoice terlihat bahwa semua aspek mengalami peningkatan. Aspek yang mengalami peningkatan jumlah skor tertinggi adalah aspek Spesifikasi (S) yaitu dari 10,5 menjadi 19,5. Sedangkan aspek yang mengalami peningkatan terendah adalah aspek Kualitas Gambar (KG). pembelajaran kooperatif tipe $G I$ berdasarkan nilai median dari kedua observer dapat dilihat pada Tabel 2. 


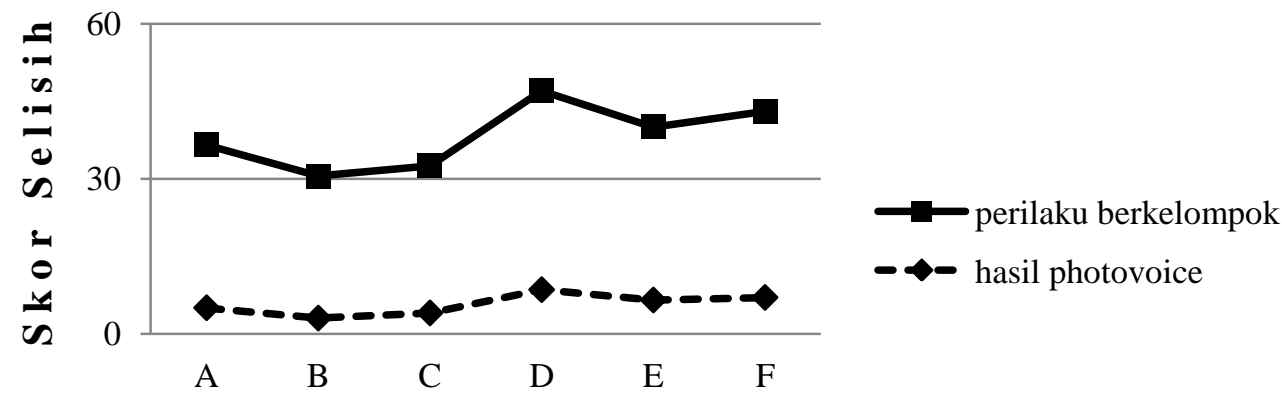

Kelompok

Gambar 1. Hubungan antara Perilaku Berkelompok dengan Hasil Photovoice Siswa Ditinjau dari Kelompok.

Berdasarkan Gambar 1, terlihat bahwa peningkatan jumlah skor pada perilaku berkelompok diikuti dengan peningkatan jumlah skor pada hasil photovoice siswa. Peningkatan jumlah skor tertinggi pada perilaku berkelompok, secara berurutan diperoleh kelompok D, kelompok F, kelompok E, kelompok A, kelompok C dan kelompok B. Sedangkan peningkatan jumlah skor pada hasil photovoice siswa, secara berurutan diperoleh kelompok D, kelompok E, kelompok F, kelompok A, kelompok B dan kelompok C.

Berdasarkan hasil uji korelasi non-parametrik menggunakan Spearman Rank-Correlation, didapatkan koefisien korelasi ( $\rho=0,928)$ yang ditunjukkan dengan tanda positif. Artinya, semakin meningkat skor perilaku berkelompok semakin meningkat pula skor hasil photovoice. Berdasarkan nilai signifikansi yang diperoleh yaitu (0,008), lebih kecil daripada probabilitas $\quad(0,008<0,01), \quad$ maka hipotesis kedua dalam penelitian ini yang menyatakan perilaku berkelompok siswa dalam pembelajaran kooperatif tipe Group Investigation (GI) dengan media photovoice berbasis lanskap budaya subak berpengaruh terhadap hasil photovoice siswa diterima.

\section{Pembahasan}

\section{Perilaku berkelompok}

Berdasarkan hasil analisis data yang telah dilakukan, masing-masing aspek perilaku berkelompok mengalami peningkatan. Setelah diuji menggunakan Wilcoxon Match Pairs diperoleh tingkat signifikansi $(\mathrm{p}<0,05)$ pada setiap aspek, yang berarti terdapat perbedaan nyata antara 
sebelum dan sesudah pembelajaran dengan menggunakan model pembelajaran kooperatif tipe GI. Hal ini menunjukkan bahwa implementasi model pembelajaran kooperatif tipe $G I$ dengan media photovoice berbasis lanskap budaya subak berpengaruh terhadap perilaku berkelompok siswa SMP Amarawati Tampaksiring. Meningkatnya aspek perilaku berkelompok siswa, dikarenakan pembelajaran kooperatif tipe $G I$ melatih siswa untuk terbiasa menempatkan diri pada lingkungan sosial, belajar menghargai pendapat orang lain, melatih keterampilan partisipasi siswa dalam proses pembelajaran, memberikan kesempatan pada siswa untuk bertukar pengalaman belajar, memotivasi siswa untuk bersaing secara sportif, melatih siswa untuk bertanggung jawab, memacu siswa untuk lebih kreatif karena melakukan kegiatan kelompok yang variatif serta melatih siswa untuk berani mengemukakan pendapatnya. Hal ini sejalan dengan hasil wawancara dengan siswa, dimana siswa mengungkapkan bahwa belajar secara berkelompok membuat mereka menjadi lebih akrab satu sama lain, lebih nyaman mengemukakan pendapat karena dengan teman sebaya, penguasaan materi lebih cepat karena saling berdiskusi, serta dapat bekerjasama dalam menyelesaikan tugas-tugas kelompoknya.

Ditinjau dari aspek perilaku berkelompok, yang mengalami peningkatan tertinggi adalah aspek peranan anggota dalam kelompok (PADK), hal ini sesuai dengan pengamatan yang dilakukan. Dimana sebelum menerapkan pembelajaran kooperatif $G I$, dalam mengerjakan tugas kelompoknya siswa cenderung kurang aktif dan kurang termotivasi. Hanya beberapa orang yang antusias dalam mengerjakan tugas, hal ini dikarenakan siswa belum terbiasa belajar di dalam kelompok sehingga egoisme masing-masing anggota masih sangat terlihat.

Setelah melakukan pembelajaran kooperatif $G I$, siswa mulai dapat berkomunikasi dengan siswa lainnya karena pada setiap tahapan pembelajaran kooperatif ini siswa dituntut untuk selalu mendiskusikan permasalahan dalam mengerjakan tugas kelompok. Sikap mendominasi juga berkurang karena setiap anggota kelompok memiliki tanggung jawab masing-masing. Misalnya pada saat 
pembelajaran di areal Subak Pulagan, siswa membagi tugas sebagai pengambil gambar, notulis, dan ada yang mencocokan temuan mereka di lapangan dengan materi ekosistem. Demikian pula pada saat presentasi, siswa membagi tugas masing-masing agar setiap anggota ikut berperan dalam mengerjakan tugas kelompoknya. Sehingga peningkatan aspek peranan anggota dalam kelompok (PADK) juga diikuti dengan peningkatan pada aspek pembagian tanggung jawab (PTJ). Hal ini sesuai dengan hasil penelitian Yuliana (2011), yang menemukan bahwa terjadi peningkatan sebesar 7,06\% setelah penerapan pembelajaran kooperatif tipe GI terhadap kemampuan afektif siswa yang mencakup penerimaan (receiving), bertanggung jawab terhadap tugas (responding), bekerjasama dalam kelompok (valuing), mendiskusikan permasalahan (organizing) dan kemampuan menyelesaikan suatu permasalahan (characterization).

Aspek-aspek perilaku berkelompok saling terkait dan mempengaruhi dalam membentuk dinamika sosial yang baik. Oleh karena itu peningkatan salah satu aspek akan diikuti oleh aspek lainnya. Aspek kualitas interaksi (KI) mengalami peningkatan sebesar 56,0, sedangkan aspek partisipasi kelompok (PK) mengalami peningkatan sebesar 40,0. Adanya keterkaitan aspek-aspek dalam perilaku berkelompok, karena kelompok merupakan kumpulan dua orang atau lebih yang saling berinteraksi untuk mencapai suatu tujuan bersama, dimana agar tercapai suatu interaksi sosial yang baik diperlukan faktor-faktor pendukung antara lain rasa simpati (ketertarikan), motivasi (dorongan), empati (rasa simpatik), sugesti (kepercayaan), imitasi (meniru), indentitas (penyesuaian diri), kontak sosial (bekerja sama) dan komunikasi (Triyanto, 2013).

Selain itu peningkatan perilaku berkelompok siswa juga dipengaruhi oleh proses belajar mengajar, jika didukung dengan pembelajaran menarik dan komunikatif tentu dapat memotivasi siswa untuk berinteraksi baik dengan guru maupun siswa lainnya. Penggunaan media inovatif berupa media photovoice, mampu membangkitkan rasa ingin tahu dan memotivasi siswa untuk membuat hasil yang sebaik-baiknya. Hal ini 
sesuai dengan hasil penelitian kualitatif oleh Perry (2009), yang menemukan bahwa pembelajaran menggunakan media photovoice merupakan pembelajaran berbasis teknologi yang praktis, sederhana dan efektif untuk meningkatkan pemahaman serta mengembangkan interaksi sosial siswa. Berdasarkan hasil wawancara, siswa mengungkapkan bahwa penggunaan media photovoice dalam pembelajaran merupakan metode baru bagi mereka, selain itu belajar menggunakan gambar lebih menarik dan mudah dimengerti. Selain penggunaan media yang inovatif serta melibatkan partisipasi aktif siswa, suasana pembelajaran juga harus kondusif dan menyenangkan agar siswa tidak merasa jenuh. Pembelajaran langsung di areal subak merupakan salah satu inovasi untuk membelajarkan siswa mengenai materi IPA khususnya biologi, sekaligus mengenal kebudayaan mereka. Manfaat belajar di areal Subak Pulagan berdasarkan wawancara dengan siswa antara lain : 1) membuat suasana pembelajaran menjadi lebih menyenangkan karena belajar dilakukan di luar kelas; 2) dapat belajar langsung dari contoh- contoh di lapangan yang berkaitan dengan materi ekosistem; 3) materi pelajaran menjadi lebih mudah diingat dan dipahami; serta 4) dapat mengenal lebih jauh tentang subak bukan hanya sebagai kebudayaan, tetapi juga sebagai media dalam pembelajaran IPA khususnya biologi. Hal ini didukung oleh penelitian Sudiana, dkk., (2009), yang menyatakan bahwa melalui pembelajaran sains biologi yang diintegrasikan dengan pengetahuan tradisional subak, siswa merasakan kegiatan belajar menjadi lebih menyenangkan dan bermakna, sebab siswa bisa mengkonstruksi pengetahuannya sendiri berdasarkan pengetahuan yang telah dimiliki sebelumnya dan pengalaman dalam kehidupan aktualnya.

\section{Pengaruh perilaku berkelompok} terhadap hasil photovoice siswa

Hasil photovoice siswa mengalami peningkatan dari sebelum dan sesudah pembelajaran menggunakan model pembelajaran kooperatif tipe $G I$, hal ini terlihat dari peningkatan jumlah skor pada masingmasing aspek penilaian photovoice. Aspek yang mengalami peningkatan tertinggi adalah Spesifikasi (S) yang mencakup kesesuaian antara tema 
(topik), gambar, serta narasi yang dibuat oleh siswa. Sebelum penerapan pembelajaran kooperatif tipe $G I$, topik serta gambar dalam pembuatan photovoice masih ditentukan oleh guru model, sehingga siswa mengalami kesulitan untuk menentukan narasi yang sesuai sehingga antara topik, foto, dan narasi yang dibuat tidak saling berkaitan. Setelah diterapkan pembelajaran kooperatif tipe $G I$, siswa diberikan wewenang untuk menentukan topik serta mengambil gambar sesuai dengan ide dan hasil diskusi kelompok. Hal ini mempermudah siswa dalam membuat narasi foto, karena siswa menentukan topiknya dari awal. Sehingga aspek spesifikasi yang mencakup keterkaitan antara topik, gambar dan narasi mengalami peningkatan yang pesat. Sedangkan aspek yang mengalami peningkatan paling rendah adalah aspek Kualitas Gambar (KG). Hal ini dikarenakan siswa masih kurang memahami bagaimana cara mengambil gambar dengan baik, selain itu beberapa obyek foto berupa hewan sedikit menyulitkan siswa untuk mengambil gambar karena obyek selalu berpindah-pindah. Tetapi hal ini tidak menjadi hambatan dalam pembuatan media photovoice, karena teknik fotografi tidak terlalu diutamakan.

Adanya keterkaitan antara perilaku berkelompok dengan hasil photovoice siswa diperkuat oleh hasil uji korelasi non-parametrik menggunakan Spearman RankCorrelation didapatkan koefisien korelasi sebesar $(0,928)$ yang ditunjukkan dengan tanda positif, dimana maknanya adalah semakin meningkat perilaku berkelompok siswa semakin meningkat pula hasil photovoice siswa tersebut, seperti yang terlihat pada Gambar 1. Berdasarkan nilai signifikansi yang diperoleh yaitu $(0,008<0,01)$, maka dapat diartikan bahwa perilaku berkelompok siswa dalam pembelajaran kooperatif tipe $G I$ dengan media photovoice berbasis lanskap budaya subak berpengaruh sangat nyata terhadap hasil photovoice siswa. Hasil tersebut didukung oleh penelitian Fernanda, $d k k$., (2012), yang menemukan bahwa terdapat hubungan yang signifikan antara kemampuan berinteraksi sosial dengan hasil belajar siswa, dimana semakin baik kemampuan berinteraksi 
sosial pada siswa maka semakin baik pula hasil belajarnya.

Keterkaitan antara perilaku berkelompok dan hasil photovoice siswa tersebut sesuai dengan aspek utama dalam pembelajaran kooperatif, yaitu : 1) motivasi artinya memberikan penghargaan terhadap kerjasama kelompok siswa untuk keberhasilannya mencapai tujuan kelompok; 2) sosial yaitu melalui belajar kelompok, siswa mampu saling berbagi pengetahuan dengan siswa lainnya; serta 3) perkembangan kognitif yaitu meningkatkan prestasi belajar siswa (Rusman, 2010). Sehingga dengan menerapkan pembelajaran kooperatif dalam penelitian ini dapat meningkatkan aspek sosial yaitu perilaku berkelompok dan berimbas positif terhadap perkembangan kognitif berupa hasil photovoice sebagai tugas akhir kelompok. Penggunaan hasil photovoice sebagai tugas akhir kelompok, didukung oleh penelitian Surata, $d k k .$, (2005), yang menemukan bahwa terdapat perbedaan hasil gambaran yang sangat nyata $(\mathrm{p}<0,000)$ antara siswa yang dibelajarkan menggunakan pendidikan lingkungan berbasis subak dengan siswa yang tidak memperoleh pembelajaran sama sekali, hal tersebut mengimplikasikan bahwa gambaran sebagai salah satu karya seni siswa dapat dipergunakan sebagai alat evaluasi pembelajaran seperti halnya tes atau soal.

Peningkatan skor tertinggi baik pada perilaku berkelompok maupun hasil photovoice diperoleh kelompok D. Berdasarkan pengamatan, sebelum diterapkan pembelajaran kooperatif tipe $G I$ kelompok D cenderung sangat pasif dalam melakukan diskusi, tugas yang diberikan yaitu pembuatan photovoice awal dikerjakan seadanya tanpa usaha maksimal dan tidak terlihat kerjasama antar anggotanya. Peningkatan pesat diperoleh kelompok ini dikarenakan adanya motivasi untuk bersaing positif dengan kelompok lainnya, selain itu penghargaan yang akan diberikan pada akhir pembelajaran ikut memacu semangat mereka untuk mencapai hasil terbaik. Hal tersebut sesuai dengan hasil wawancara dengan siswa, dimana siswa menyatakan bahwa tugas yang diberikan yaitu membuat media sendiri berupa photovoice memacu mereka untuk berlomba-lomba membuat hasil terbaik dibandingkan dengan kelompok lainnya. Sedangkan 
peningkatan baik perilaku berkelompok maupun hasil photovoice terendah diperoleh kelompok $\mathrm{B}$, hal ini diakibatkan kurangnya komunikasi serta lemahnya kerjasama antar anggota dalam kelompok. Selain itu sikap mendominasi juga sangat nampak pada kelompok ini, lemahnya beberapa aspek perilaku berkelompok dalam kelompok B disebabkan karena kurangnya kesadaran anggota untuk aktif dalam mengerjakan tugas kelompoknya. Sehingga hal tersebut diatasi dengan pembagian tanggung jawab agar tugas masing-masing individu merata.

Tujuan pembentukan suatu kelompok salah satunya adalah adanya keinginan untuk mencapai suatu tujuan bersama. Demikian pula pada kelompok belajar, di dalam kegiatan berkelompok siswa harus menjalin interaksi serta kerjasama yang baik untuk mencapai keberhasilan tugasnya. Interaksi dalam kelompok salah satunya terjadi melalui proses komunikasi, dengan adanya komunikasi siswa dapat saling bertukar ide atau pendapat, mengajukan pertanyaan serta mencari solusi untuk memecahkan permasalahan. Partisipasi kelompok dapat terlihat pada saat kegiatan diskusi, siswa saling mengemukakan pendapat dan ide mereka dalam pembuatan tugas, walaupun sering terjadi perbedaan dan adu argumen, tetapi hal ini menunjukkan terjadi interaksi yang baik dalam kelompok tersebut. Selain interaksi, kerjasama dalam kelompok juga sangat diperlukan untuk mencapai hasil yang maksimal. Kerjasama dalam kelompok siswa tercermin dari usaha setiap anggota untuk menyatukan ide-ide yang berbeda agar menjadi berkesinambungan, serta pada saat presentasi hasil photovoice siswa saling melengkapi dalam menjawab pertanyaan yang diajukan oleh kelompok lain maupun oleh guru model. Pentingnya kerjasama dalam pencapaian tujuan kelompok serta mengembangkan aspek siswa sesuai dengan hasil penelitian Restyowati, $d k k$., (2010), yang menemukan adanya peningkatan skor kemampuan berinteraksi sosial siswa dari pretest ke posttet setelah diberikan perlakuan bimbingan kelompok dengan teknik permainan kerjasama. 


\section{PENUTUP}

\section{Simpulan}

Adapun simpulan dari penelitian ini adalah pembelajaran kooperatif tipe GI dengan media photovoice berbasis subak berpengaruh nyata $(\mathrm{p}=0,028<0,05) \quad$ terhadap perilaku berkelompok siswa SMP Amarawati Tampaksiring, serta perilaku berkelompok dalam pembelajaran kooperatif tipe GI dengan media photovoice berbasis subak berpengaruh sangat nyata $(\mathrm{p}=0,008<0,01) \quad$ terhadap hasil photovoice siswa.

\section{Saran}

Berdasarkan temuan dalam
penelitian ini, maka dapat
disampaikan beberapa saran sebagai
berikut : 1) Diharapkan pembelajaran
kooperatif tipe GI dengan media
photovoice berbasis subak dapat
dijadikan salah satu model
pembelajaran alternatif oleh guru
dalam mengembangkan aspek perilaku
berkelompok siswa; Sehingga melatih
siswa untuk ikut berpartisipasi secara
aktif dalam kegiatan pembelajaran; 2)
Diharapkan kepada guru untuk
menerapkan pembelajaran kooperatif
berbasis media pembelajaran yang

dikaitkan dengan contoh langsung di lingkungan sekitar dalam mata pelajaran lain untuk membangun proses pembelajaran yang bermakna dan menyenangkan; Diharapkan bagi peneliti selanjutnya untuk melakukan penelitian sejenis dengan mengembangkan variabel-variabel penelitian yang lebih bervariasi sehingga dapat menambah inovasi pembelajaran dalam dunia pendidikan.

\section{DAFTAR PUSTAKA}

Fernanda, M. M., Sano, A. S., \& Nurfarhanah.

(2012). Hubungan antara kemampuan berinteraksi sosial dengan hasil belajar. Jurnal ilmiah konseling. Diunduh dari http://ejournal.unp.ac.id/index. php/konselor. Pada tanggal 24 Mei 2013.

Murti, B. (2011). Validitas dan reliabilitas pengukuran. Diunduh dari http://www.google.co.id/url?sa $=\mathrm{t} \& \mathrm{rct}=\mathrm{j} \& \mathrm{q}=\&$ esrc $=\mathrm{s} \&$ source $=$ web $\& \mathrm{~cd}=1 \&$ ved $=0 \mathrm{CCoQFjAA}$ \&url=http $\% 3 \mathrm{~A} \% 2 \mathrm{~F} \% 2 \mathrm{Ffk}$.uns. ac.id\%2Findex.php\%2Fdownlo ad\%2Ffile $\% 2$ F61 \&ei=4SHUY TcAcTqrAfZrIDABw\&usg=A FQjCNGFXL2esz2gqpn81AT_ LH9JWHjYVA\&bvm=bv.459 60087,d.bmk. Pada tanggal 25 April 2013.

Nelson, E., \& Christensen, K. (2012). In the middle: how our students experience learning at school 
and beyond. Diunduh dari www.teacherswork.ac.nz/journal /.../nelson.pdf. Pada tanggal 15 September 2012.

Nurdin, R. (2012). Studi komparatif penerapan model pembelajaran kooperatif tipe gi dengan konvensional pada pembelajaran ilmu statistika di SMKN 1 Cilaku (Skripsi, Universitas Pendidikan Indonesia). Diunduh dari http://repository.upi.edu/operat or/upload/s_mat_0706564_cha pter1.pdf. Pada tanggal 17 September 2012.

Perry, B. (2009). Creating a culture of community in online courses. Diunduh dari http://auspace.athabascau.ca/ha ndle/2149/2159. Pada tanggal 20 Januari 2013.

Restyowati, D., \& Naqiyah, N. (2012). Penerapan teknik permainan kerja sama dalam bimbingan kelompok untuk meningkatkan kemampuan interaksi sosial pada siswa. Jurnal Psikologi Pendidikan dan Bimbingan 11( 2). Diunduh dari http://ppb.jurnal.unesa.ac.id/74 _421/penerapan-teknikpermainan-kerja-sama-dalambimbingan-kelompok-untukmeningkatkan-kemampuaninteraksi-sosial-pada-siswa. Pada tanggal 29 Mei 2013.

Rusman. (2010). Model-model pembelajaran mengembangkan profesionalisme guru (edisi kedua). Jakarta : Raja Grafindo.
Sudiana, I. M, \& Surata, I. K. (2009). Pendidikan dan latihan merancang pembelajaran ipa biologi melalui pendekatan keterampilan proses berbasis pengetahuan tardisional dan lingkungan subak bagi guru SMP. Jurnal Bakti Saraswati 1 (2). Diperoleh dari http://www.unmas.ac.id/PDF/J URNA-JBS-VOL-01-NO-02SEPTEMBER-2011.pdf. Pada tanggal 22 Mei 2013.

Surata, S. P. K, \& Seniwati, N. P. (2005). Kegiatan menggambar berbasis subak sebagai model pendidikan lingkungan bagi siswa SD di Bali. Jurnal Pendidikan dan Pembelajaran 13(2), 166-174.

Surata, S. P. K. (2011). Rubrik pengamatan perilaku berkelompok. (Rubrik tidak dipublikasikan). Universitas Mahasaraswati Denpasar, Denpasar.

Triyanto. (2013). Hubungan sosial. Diunduh dari http://geografi9.blogspot.com/2013/01/hubun gan-sosial.html. Pada tanggal 3 Mei 2013.

Yuliana. (2011). Penerapan pembelajaran kooperatif group investigation (GI) untuk meningkatkan kemampuan afektif siswa dalam pembelajaran biologi siswa kelas VII A SMP Negeri 16 Surakarta tahun ajaran 2010/2011. Diunduh dari 
http://biologi.fkip.uns.ac.id/wp

content/uploads/2011/05/30x.p

df. Pada tanggal 3 Mei 2013.

Zlem, J. (2012). Rubric photovoice.

Diunduh

dari

http://www.rcampus.com/rubrics howc.cfm? code $=\mathrm{Q} 4 \mathrm{X} 87 \mathrm{~B} \& \mathrm{sp}=\mathrm{t}$

rue. Pada tanggal 25 November

2012. 